\title{
Predicting grain size distributions in perovskite-structured Ba0.5Sr0.5Co0.8Fe0.2O3- oxygen transport membranes
}

DOI:

10.1080/17436753.2018.1434955

\section{Document Version}

Accepted author manuscript

Link to publication record in Manchester Research Explorer

\section{Citation for published version (APA):}

Wang, L., Dou, R., Wang, G., Li, Y., Bai, M., Hall, D., \& Chen, Y. (2018). Predicting grain size distributions in perovskite-structured $\mathrm{Ba}$ Sr $\mathrm{Co}$ Fe, $\mathrm{O}$ oxygen transport membranes. Advances in Applied Ceramics, 17. https://doi.org/10.1080/17436953.2818.9.434955

\section{Published in:}

Advances in Applied Ceramics

\section{Citing this paper}

Please note that where the full-text provided on Manchester Research Explorer is the Author Accepted Manuscript or Proof version this may differ from the final Published version. If citing, it is advised that you check and use the publisher's definitive version.

\section{General rights}

Copyright and moral rights for the publications made accessible in the Research Explorer are retained by the authors and/or other copyright owners and it is a condition of accessing publications that users recognise and abide by the legal requirements associated with these rights.

\section{Takedown policy}

If you believe that this document breaches copyright please refer to the University of Manchester's Takedown Procedures [http://man.ac.uk/04Y6Bo] or contact uml.scholarlycommunications@manchester.ac.uk providing relevant details, so we can investigate your claim.

\section{OPEN ACCESS}


$6{ }^{1}$ Technology and Engineering Centre for Space Utilisation, Chinese Academy of

7 Science, Beijing, 10094, PR China

$8 \quad{ }^{2}$ School of Materials, University of Manchester, Manchester, M13 9PL, UK

9 *Corresponding authors at: Technology and Engineering Centre for Space Utilisation,

10 Chinese Academy of Science, Beijing, 10094, PR China

11 E-mail address: li.wang-5@ postgrad.manchester.ac.uk (Li Wang)

12

\section{Abstract}

16 This study is conducted over a $3 \times 3$ time-temperature matrix on

$17 \mathrm{Ba}_{0.5} \mathrm{Sr}_{0.5} \mathrm{Co}_{0.8} \mathrm{Fe}_{0.2} \mathrm{O}_{3-\delta}(\mathrm{BSCF})$ ceramics, and sintered bodies above $93 \%$ dense are

18 obtained. The electron backscatter diffraction (EBSD) band contrast micrographs of

19 the polished sintered samples are analysed for characterising the grain size

20 distributions. This study develops an algorithm for predicting the grain size

21 distributions (GSDs) of BSCF dependence of sintering condition (time and

22 temperature). In addition, the GSDs predicted by the algorithm agree reasonably with

23 those experimentally observed. When individual grain size is nondimensionalised by

24 the median grain size, the GSDs data of all BSCF samples reduces to a single 
1 self-similar GSD curve. The median grain size is predicted by the classical kinetics

2 equation, $D^{n}=t K_{0} \exp (-Q / R T)$.

3 Keywords: BSCF; Grain growth kinetics; Grain size distribution; Microstructure

\section{Introduction}

5 Mixed ionic and electronic conducting (MIEC) materials have attracted great attention

6 to be studied due to their application in oxygen separation $[1,2]$ and solid oxide fuel

7 cells $[3,4]$. Among these MIEC materials, the perovskite-structured

$8 \mathrm{Ba}_{0.5} \mathrm{Sr}_{0.5} \mathrm{Co}_{0.8} \mathrm{Fe}_{0.2} \mathrm{O}_{3-\delta}$ (BSCF) was found to be a promising material for oxygen

9 permeation[5]. Generally, the oxygen permeability of ceramic membranes highly

10 depends on many factors, including compositions, thickness, microstructure, and

11 temperature[6]. Many studies have shown that the permeability of the membranes was

12 greatly influenced by grain size. For example, the oxygen permeability of

$13 \mathrm{SrCo}_{0.8} \mathrm{Fe}_{0.2} \mathrm{O}_{3-\delta}$ increases significantly with decreasing grain size, because grain

14 boundary hinders the transfer of oxygen ions[7]. However, the permeability of

$15 \mathrm{SrCo}(\mathrm{Fe}, \mathrm{Cu}) \mathrm{O}_{3-\delta}[8]$ and $\mathrm{Ba}_{0.5} \mathrm{Sr}_{0.5} \mathrm{Fe}_{0.8} \mathrm{Zn}_{0.2} \mathrm{O}_{3-\delta}[9]$ materials increase with increasing

16 the average grain size. In the case of BSCF, Arnold et al. [10]have reported that the

17 permeability increases with decreasing the average grain size. On the contrary, Wang

18 et al. have reported the permeability increases considerably with increasing average

19 grain size[11]. Other properties of polycrystalline ceramics also highly depend on the 
1 microstructure, so that it is very important in a general sense to fundamentally

2 understand the microstructural development of ceramics. In the case of electrical

3 property, it has been reported that the area specific resistance (ASR) of BSCF

4 materials with nano-scale grain sizes is much lower than those with micro-scale grain

5 sizes[12]. Although there is no literature to report the influence of grain size on

6 mechanical properties of BSCF, fracture stress and fracture toughness were highly

7 related to grain size for some other ceramic materials[13]. For example, the strength

$8 \mathrm{of}_{3} \mathrm{SiC}_{2}$ increases with decreasing the average grain size in the temperature range of

$925{ }^{\circ} \mathrm{C}$ to $1300{ }^{\circ} \mathrm{C}[14]$ and fracture toughness of $\mathrm{Si}_{3} \mathrm{~N}_{4}$ with broader grain size

10 distribution was higher than that with narrower one due to crack deflection[13].

11 Therefore, the properties of ceramics can be modified by these microstructural

12 characteristics.

13 For most of these works mentioned above, an average grain size obtained from

14 scanning electron micrographs is usually determined by the lineal intercept

15 technique[15]. Image analysers are normally being used to quantify the grain

16 sizes[16]. The average grain size thus measured was used to analyse an activation of

17 the kinetic parameters of BSCF grain growth, namely the apparent activation energy

18 and the kinetic grain growth exponent. These parameters can be determined from the

19 following equation[17] 
1 where $D$ is the average grain size $(\mu \mathrm{m})$ after sintering the specimen for time $t$ at $\mathrm{T}$

2 temperature; $\mathrm{Q}$ the apparent activation energy; $n$ grain growth exponent; $K_{0}$ is a

3 constant; $\mathrm{R}$ the gas constant; and $T$ the absolute temperature.

4 In this way, only an average grain size representing the multitude of grains of sintered

5 bodies is related with the sintering time-temperature conditions. However, the sintered

6 bodies normally have a wide distribution of grain sizes. In other words, larger grains

7 and smaller ones exist at the same time. Therefore, how grain size distributions in a

8 ceramic body influenced by the sintering time-temperature schedule need to be

9 investigated.

10 As introduced above, grain sizes and their distributions in sintered bodies are worthy

11 studying. To the best of our knowledge, there is no relevant report about the

12 prediction of $\mathrm{BSCF}$ grain size distributions because of the challenge in preparing

13 appropriate samples for image based analysis. In order to attain a deeper

14 understanding of grain size distributions of BSCF materials, the parameters of grain

15 growth kinetics used to predict its grain size distributions and the requirement for

16 tailoring ceramic microstructures, the present study was conducted with the technical

17 support of electron backscatter diffraction (EBSD) to fulfill the accurate grain size

18 and grain boundary determination without special sample preparation process, like

19 chemical or thermal etching $\left(>800{ }^{\circ} \mathrm{C}\right)$ which could introduce the error in grain size

20 in forms of unexpected grain boundary damage or grain growth during the etching 
1 process.

22 Experimental procedure

$3 \mathrm{Ba}_{0.5} \mathrm{Sr}_{0.5} \mathrm{Co}_{0.8} \mathrm{Fe}_{0.2} \mathrm{O}_{3-\delta}$ powders were supplied by Treibacher Industrie AG, Austria.

4 The powder was packed in a cylindrical stainless steel die with a diameter $28 \mathrm{~mm}$, and

5 uniaxially pressed under a pressure of $100 \mathrm{MPa}$. The BSCF samples were sintered as

6 the following $3 \times 3$ temperature-time matrix. The sintering temperatures were $1075^{\circ} \mathrm{C}$,

$7 \quad 1100^{\circ} \mathrm{C}$ and $1125^{\circ} \mathrm{C}$ and the dwell times were 5,10 , and 24 hours. The heating rate

8 and the cooling rate during the process of sintering were set to $180^{\circ} \mathrm{C} /$ hour. The

9 relative densities of all the BSCF samples determined by the Archimedes method in

10 distilled water were over 93\%. The samples were then ground using several different

11 sizes of $\mathrm{SiC}$ grinding papers from $\mathrm{P} 400$ to P1200, and then polished with diamond

12 paste descending from $6 \mu \mathrm{m}$ to $0.25 \mu \mathrm{m}$. The colloidal silica was used for 15 minutes

13 in the final polishing stage. The phase composition of all the BSCF was determined to

14 be a single cubic phase by X-ray diffraction. Grain sizes were analysed by scanning

15 electron microscopy (SEM; Quanta FEG-650, FEI) equipped with electron

16 backscatter diffraction (EBSD, NordlysNano, Oxford Instruments). The grain size

17 was analysed by EBSD method using the area counting technique. To be more

18 specific, the diameter was calculated by the equivalent area $\left(D=\sqrt{\frac{4 S}{\pi}}\right)$. A large

19 number of grains were analysed to ensure that a representative average value could be

20 measured for the samples 


\section{$1 \quad 3$ Results and discussion}

\section{3.1 Comparing the grain size distributions in the 3 sintered BSCF ceramics}

4 Figure 1 shows the EBSD band contrast micrographs of the same sintered samples at

5 two different fields. It can be clearly inferred that microstructural features in these two

6 fields are very similar in appearance. Figure 2 shows the relationship between the

7 cumulative frequencies of the grain undersize against the grain size for the two

8 electronic micrographs of Figure 1. It is clearly observed that the microstructures

9 exhibit a close quantitative match. The overlap of grain size distributions in Figure 2

10 proves that the grain size analysis by EBSD method is repeatable and reproducible.

11 This indicates that EBSD method is suitable for making further analysis in this study.

12 Figure 3 shows the grain size distributions of the sintered samples obtained under

13 various sintering conditions. These four plots were selected because they were

14 reasonably far apart from each other, making it possible clearly distinguish the data

15 points. It is clearly evident from the plots presented in Figure 3 and Figure 4, that,

16 whereas the shape of the grain size distribution profile of each curve remains

17 essentially similar, the grain size distribution curve shifts toward the coarser end of

18 the size profile as a function of prolonging dwell time and/or increasing temperature.

19 Then, it is possible to give basically the same grain size distribution under appropriate 
1 conditions for different combinations of time and temperature. It can be inferred from

2 Equation (1) that the combination of a high sintering temperature and short dwell time

3 would give the same average grain size and grain size distribution as that of a

4 relatively lower temperature and longer time.

5 Unexpectedly, even within the inadequate number of the sintered bodies, this

6 provisional study was demonstrated experimentally. Figure 5 shows that the EBSD

7 band contrast micrographs of microstructures of the sintered bodies under different

8 conditions look visually similar. It has been demonstrated that the grain size

9 distributions of these two samples in Figure 5 are plotted similarly, as shown in Figure 106

\section{$11 \quad 3.2$ Self-similar grain size distributions in sintered BSCF}

12 It is noted above that while the plot profile tends towards a coarse grain size range

13 during grain growth, the shape of the grain size distribution profiles remain similar in

14 Figure 3 and Figure 4. When the grain size distributions of these samples are replotted

15 based on a nondimensionalised size, defined as the median size of the individual

16 distribution, several plots are obtained as shown in Figure 7. Grain size distributions

17 with this characteristic are regarded as self-similar size spectra. Self-similar

18 characteristics suggests that the same dominant mechanism governs grain growth

19 kinetics[16]. 
1 For the grain size distribution curves in Figure 7, the nondimensional grain size is

2 defined as[16]

$$
X=\frac{x}{x_{0.5}}
$$

4 where $\mathrm{X}$ is the defined dimensionless grain size corresponding to the grain with a size

$5 x(\mu \mathrm{m})$, and is the number-based median size $(\mu \mathrm{m})$ of the distribution.

6 Figure 7 shows the dimensionless grain size distributions for the data obtained under

7 different sintering conditions. As replotted in this way, the different GSD curves

8 shown in Figure 7(A) and 7(B) overlap into a single curve in Figure 7(C) and 7(D),

9 respectively. Thus, the standard of self-similarity can be used in sintered bodies as

10 well, which are consisting of numerous connected grains arranged in this system[16].

11 As aforementioned the dominant grain growth mechanism in the systems with

12 self-similarity, this implies that the appropriate time-temperature region for normal

13 grain growth can be predicted. Self-similarity for ceramics during grain growth has

14 been reported. For example, Burke et al. [18] have reported that the shape of the grain

15 size distribution curve does not depend on the grain size. Self-similar grain size

16 distributions suggest that the nondimensional grain size distributions in sintered

17 bodies for the BSCF ceramics are irrespective of the sintering histories. It can be

18 inferred that with respect to the width of the distribution, the ratio of the largest grain

19 to the smallest grain can be irrespective of the sintering history. Therefore, 
1 self-similarity has important implications, although a limited range of sintering

2 conditions are used in this study. First, when the sintering temperature-time

3 programmes are changed, it is accompanied by translation of the whole grain size

4 distribution plot horizontally along the temperature axis rather than shifting any point

5 in the plot. Second, the single measurement of any distribution, specifically its median

6 size, can predict the entire grain size distribution if the characteristic self-similarity

7 and grain size distributions plots have been already obtained. This phenomena is

8 also observed in alumina[16].

\section{$9 \quad 3.3$ Predicting the complete GSDs using a kinetics}

10 approach

11 Therefore, the object of predicting the grain size distribution is simplified to that of

12 obtaining the median sizes as a function of the sintering condition. Then, the predicted

13 median size is multiplied by the dimensionless grain size in the self-similar GSD

14 curve, the complete GSD of BSCF are obtained.

15 (1)Time dependence

16 Figure 8 shows the time dependence of the grain-growth kinetics as given in Equation

17 (1). The slopes of these three lines are around 0.33 . It indicates that the value of grain

18 growth exponent is 3 . This means that the value $\mathrm{n}$ of grain growth exponent equals 3 ,

19 which is consistent with that obtained by other groups $(n=3.1)[19]$ and other related 
1 perovskite-structured materials such as $\operatorname{PrBaCo}_{2} \mathrm{O}_{5+\delta}(\mathrm{n}=3)$ sintered at $1150^{\circ} \mathrm{C}$ from 6

2 to 48 hours[17].

3 (2)Temperature Dependence

4 According to the Equation (1), a plot of the logarithm of the median versus the

5 reciprocal of the sintering temperature (K) should give a straight line having a

6 negative slope and the activation energy is determined by the slope of the curve.

7 Figure 9 shows the Arrhenius plot for the temperature dependence of grain growth.

8 For the sintered BSCF ceramics, the activation energy (Q) for the grain kinetics in

9 was calculated to be $583.6 \pm 15 \mathrm{~kJ} / \mathrm{mol}$ from the Arrhenius plot. Although Salehi et

10 al.[20], Baumann et al.[21] and Yoon et al.[22] have not reported activation energies

11 for grain growth of BSCF, analysing their data yields activation energies in the range

12 from 372 to $741 \mathrm{~kJ} / \mathrm{mol}$ as plotted in Figure 9(B), which fairly agree with the result in

13 this study.

$14 \quad 3.4 \quad$ Grain size distributions-predicted versus 15 experimental

16 As discussed above, the procedures for predicting the grain size distributions are

17 developed as the following: (1) Produce the dimensionless GSD plot from the selected

18 sintering experiments under different sintering conditions; (2) Calculate the activation

19 energy (Q) for the grain growth from the Arrhenius-type equation and estimate the 
1 grain growth exponent (n); (3) Estimate the median size of the GSD at any preset

2 sintering condition using the expression, $D^{n}=t K \exp (-Q / R T)$; (4) Develop the

3 nondimensional grain size in the self-similar plot by the calculated median size. The

4 plot will give the predicted GSD curve of BSCF sintered under particular condition.

5 Figure 10 shows that the GSDs predicted using the algorithm was in good agreement

6 with that experimentally obtained under different time-temperature conditions. This

7 suggests that the algorithm can be used for predicting the grain size distribution of

8 BSCF.

\section{Conclusions}

10 This study is conducted on BSCF ceramics with densities above 93\%, and the

11 experimental condition covers a $3 \times 3$ time-temperature matrix. All the data regarding

12 grain size distributions is analysed from the EBSD band contrast micrographs of the

13 polished samples. Subsequently, based on the processed data from the experimental

14 range, an appropriate prediction of the grain size distribution with respect to

15 temperature and dwell time is made. All the important conclusions of this study are as

16 follows:

17 (1) A combination of higher sintering temperature and shorter dwell time gives GSDs

18 the similar with those acquired from a combination of relatively lower

19 temperature and longer time for the investigated BSCF system. 
1 (2) When the individual grain size is nondimensionalised by its median size, the

2 several nondimensional grain size distributions curves reduce to a single

3 self-similar profile. Additionally, the grain size distribution curves shift toward the

4 coarser end of the size profile as a function of prolonging sintering time and/or

$5 \quad$ increasing temperature.

6 (3) The grain growth exponent $n$ is determined to be 3 . The activation energy for

7 grain growth of BSCF is calculated to be $583.6 \mathrm{~kJ} / \mathrm{mol}$ by an Arrhenius equation.

8 (4) Based on these observations, an algorithm is proposed for predicting the complete

9 grain size distribution as a function of the sintering time-temperature plot, and the prediction of GSDs agrees reasonably well with those experimentally obtained.

11 These conclusions above are useful for predicting the grain size distribution with

12 limited experiments and valuable information is provided for designing the 13 microstructure of BSCF materials.

\section{Acknowledgements}

15 This work was partially supported by the Technology and Engineering Centre for

16 Space Utilisation(CSU), Beijing, China, under the contract No. CSU-QZKT-201708. 


\section{References}

2 1. Badwal SPS., and Ciacchi FT, Ceramic membrane technologies for oxygen separation. Advanced Materials, 2001. 13(12 - 13): p. 993-996.

2. Shao Z, Xiong G, Dong H, et al. Synthesis, oxygen permeation study and membrane performance of a $\mathrm{Ba}_{0.5} \mathrm{Sr}_{0.5} \mathrm{Co}_{0.8} \mathrm{Fe}_{0.2} \mathrm{O}_{3-\delta}$ oxygen-permeable dense ceramic reactor for partial oxidation of methane to syngas. Separation and purification technology, 2001. 25(1): p. 97-116.

3. Shao Z, and Haile SM, A high-performance cathode for the next generation of solid-oxide fuel cells. Nature, 2004. 431(7005): p. 170-173.

4. Chen $\mathrm{CH}$, Chang $\mathrm{CL}$, and Hwang $\mathrm{BH}$, Electrochemical and microstructure characteristics of $\mathrm{Ba}_{0.5} \mathrm{Sr}_{0.5} \mathrm{CO}_{0.8} \mathrm{Fe}_{0.2 \mathrm{O}} \mathrm{O}_{3-\delta}(\mathrm{BSCF})$ cathodes prepared by citrate precursor method for SOFCs. Materials Chemistry and Physics, 2009. 115(1): p. $478-482$.

5. Shao Z, Yang W, Cong Y, et al., Investigation of the permeation behavior and stability of a $\mathrm{Ba}_{0.5} \mathrm{Sr}_{0.5} \mathrm{Co}_{0.8} \mathrm{Fe}_{0.2} \mathrm{O}_{3-\delta}$ oxygen membrane. Journal of Membrane Science, 2000. 172(1): p. 177-188.

6. Tan L, Gu X, Yang L, et al., Influence of sintering condition on crystal structure, microstructure, and oxygen permeability of perovskite-related type $\mathrm{Ba}_{0.55} \mathrm{Sr}_{0.5} \mathrm{Co}_{0.8} \mathrm{Fe}_{0.2} \mathrm{O}_{3-\delta}$ membranes. Separation and purification technology, 2003. 32(1): p. 307-312.

7. Zhang K, Yang Y, Ponnusamy A, et al., Effect of microstructure on oxygen permeation in $\mathrm{SrCo}_{0.8} \mathrm{Fe}_{0.2} \mathrm{O}_{3-\delta}$. Journal of materials science, 1999. 34(6): $\mathrm{p}$. 1367-1372.

8. Kharton V, Tikhonovich V, Shuangbao L, et al., Ceramic microstructure and oxygen permeability of $\mathrm{SrCo}(\mathrm{Fe}, \mathrm{M}) \mathrm{O}_{3-\delta}(\mathrm{M}=\mathrm{Cu}$ or $\mathrm{Cr})$ perovskite membranes. Journal of the Electrochemical Society, 1998. 145(4): p. 1363-1373.

9. Martynczuk J, Arnold $\mathrm{M}$, and Feldhoff $\mathrm{A}$, Influence of grain size on the

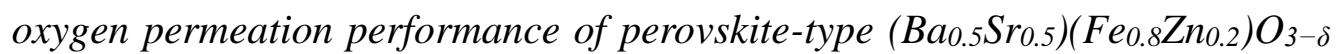
membranes. Journal of Membrane Science, 2008. 322(2): p. 375-382.

10. Arnold M, Martynczuk K, Efimove H, et al., Grain boundaries as barrier for oxygen transport in perovskite-type membranes. Journal of Membrane Science, 2008. 316(1): p. 137-144.

11. Wang H, Tablet C, Feldhoff A, et al., Investigation of phase structure, sintering, and permeability of perovskite-type $\mathrm{Ba}_{0.5} \mathrm{Sr}_{0.5} \mathrm{Co}_{0.8} \mathrm{Fe}_{0.2} \mathrm{O}_{3-\delta}$ membranes. Journal of Membrane Science, 2005. 262(1): p. 20-26.

12. Hieu NT, Park J, and Tae B, Synthesis and characterization of nanofiber-structured $\mathrm{Ba}_{0.5 \mathrm{~S}} \mathrm{Sr}_{0.5} \mathrm{Co}_{0.8} \mathrm{Fe}_{0.2} \mathrm{O}_{3-\delta}$ perovskite oxide used as a cathode material for low-temperature solid oxide fuel cells. Materials Science and Engineering: B, 2012. 177(2): p. 205-209.

13. Kawai C, Effect of grain size distribution on the strength of porous $\mathrm{Si}_{3} \mathrm{~N}_{4}$ 
ceramics composed of elongated $\beta$-Si ${ }_{3} N_{4}$ grains. Journal of materials science, 2001. 36(23): p. 5713-5717.

14. El - Raghy T, Barsoum MW, Zavaliangos A, et al., Processing and mechanical properties of $\mathrm{Ti}_{3} \mathrm{SiC}_{2}$ : II, effect of grain size and deformation temperature. Journal of the American Ceramic Society, 1999. 82(10): p. 2855-2860.

15. Wurst J, and Nelson J, Lineal Intercept Technique for Measuring Grain Size in Two - Phase Polycrystalline Ceramics. Journal of the American Ceramic Society, 1972. 55(2): p. 109-109.

16. Venkataraman KS, and DiMilia RA, Predicting the Grain - Size Distributions in High - Density, High - Purity Alumina Ceramics. Journal of the American Ceramic Society, 1989. 72(1): p. 33-39.

17. Burriel M, Peña-Martinez J, Chater RJ, et al., Anisotropic oxygen ion diffusion in layered $\mathrm{PrBaCo}_{2} \mathrm{O}_{5+\delta}$. Chemistry of Materials, 2012. 24(3): p. 613-621.

18. Burke J, and Turnbull D, Recrystallization and grain growth. Progress in metal physics, 1952. 3: p. 220-292.

19. Klande T, Ravkina O, and Feldhoff A, Effect of microstructure on oxygen permeation of $\mathrm{Ba}_{0.5} \mathrm{Sr}_{0.5} \mathrm{CoO}_{0.8} \mathrm{Fe}_{0.2} \mathrm{O}_{3-\delta}$ and $\mathrm{SrCo}_{0.8} \mathrm{Fe}_{0.2} \mathrm{O}_{3-\delta}$ membranes. Journal of the European Ceramic Society, 2013. 33(6): p. 1129-1136.

20. Salehi M, Clemens F, Praff EM, et al., A case study of the effect of grain size on the oxygen permeation flux of BSCF disk-shaped membrane fabricated by thermoplastic processing. Journal of Membrane Science, 2011. 382(1): p. 186-193.

21. Baumann S, Schulze-Kuppers F, Roitsch M, et al., Influence of sintering conditions on microstructure and oxygen permeation of $\mathrm{Ba}_{0.5} \mathrm{Sr}_{0.5} \mathrm{Co}_{0.8} \mathrm{Fe}_{0.2} \mathrm{O}_{3-\delta}$ (BSCF) oxygen transport membranes. Journal of Membrane Science, 2010. 359(1-2): p. 102-109.

22. Yoon JS, Yoon MY, Lee EJ, et al., Influence of $\mathrm{Ce}_{0.9} \mathrm{Gd}_{0.1} \mathrm{O}_{2-\delta}$ particles on microstructure and oxygen permeability of $\mathrm{Ba}_{0.5} \mathrm{Sr}_{0.5} \mathrm{Co}_{0.8} \mathrm{Fe}_{0.2} \mathrm{O}_{3-\delta}$ composite membrane. Solid State Ionics, 2010. 181(29-30): p. 1387-1393. 


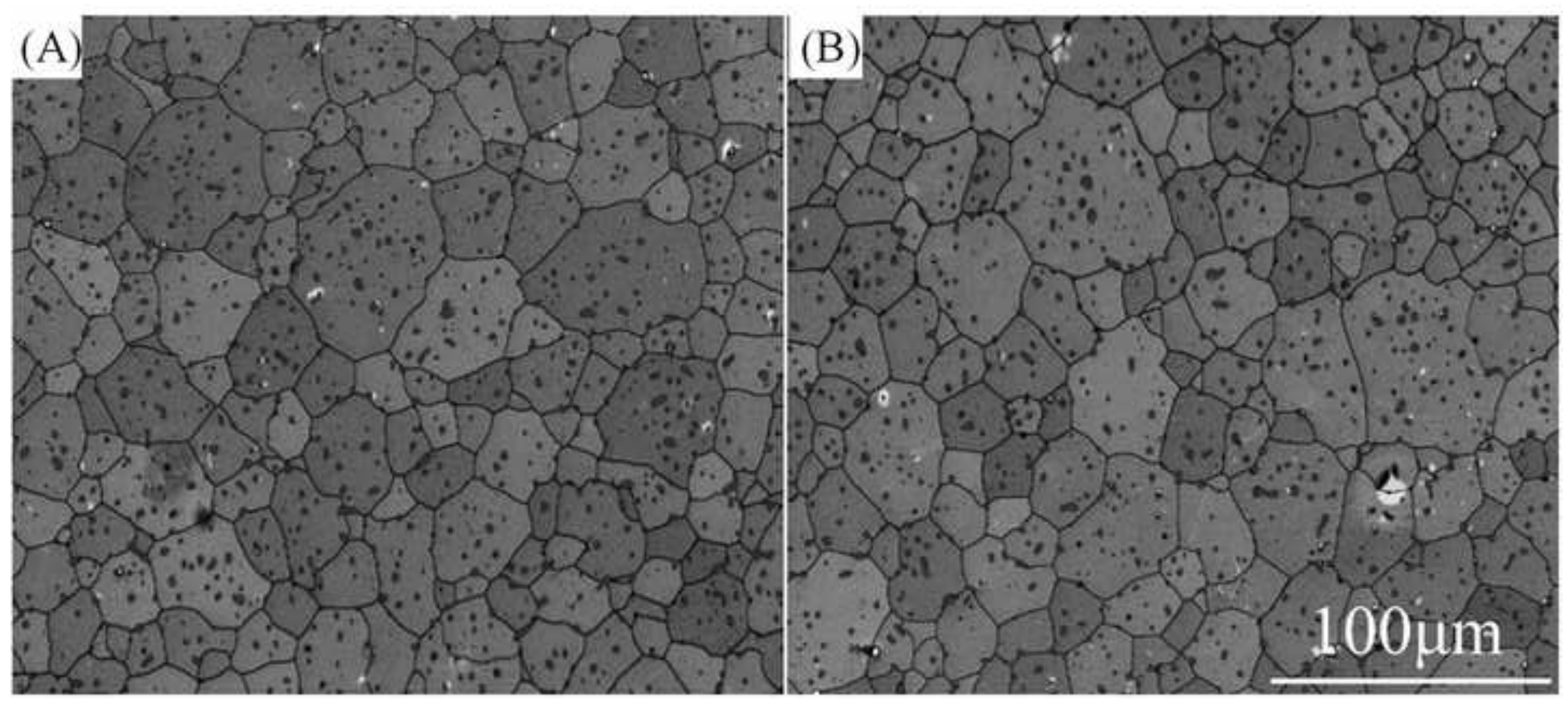


Click here to download Non-colour figure Figure 2.tif $\underline{\underline{ }}$

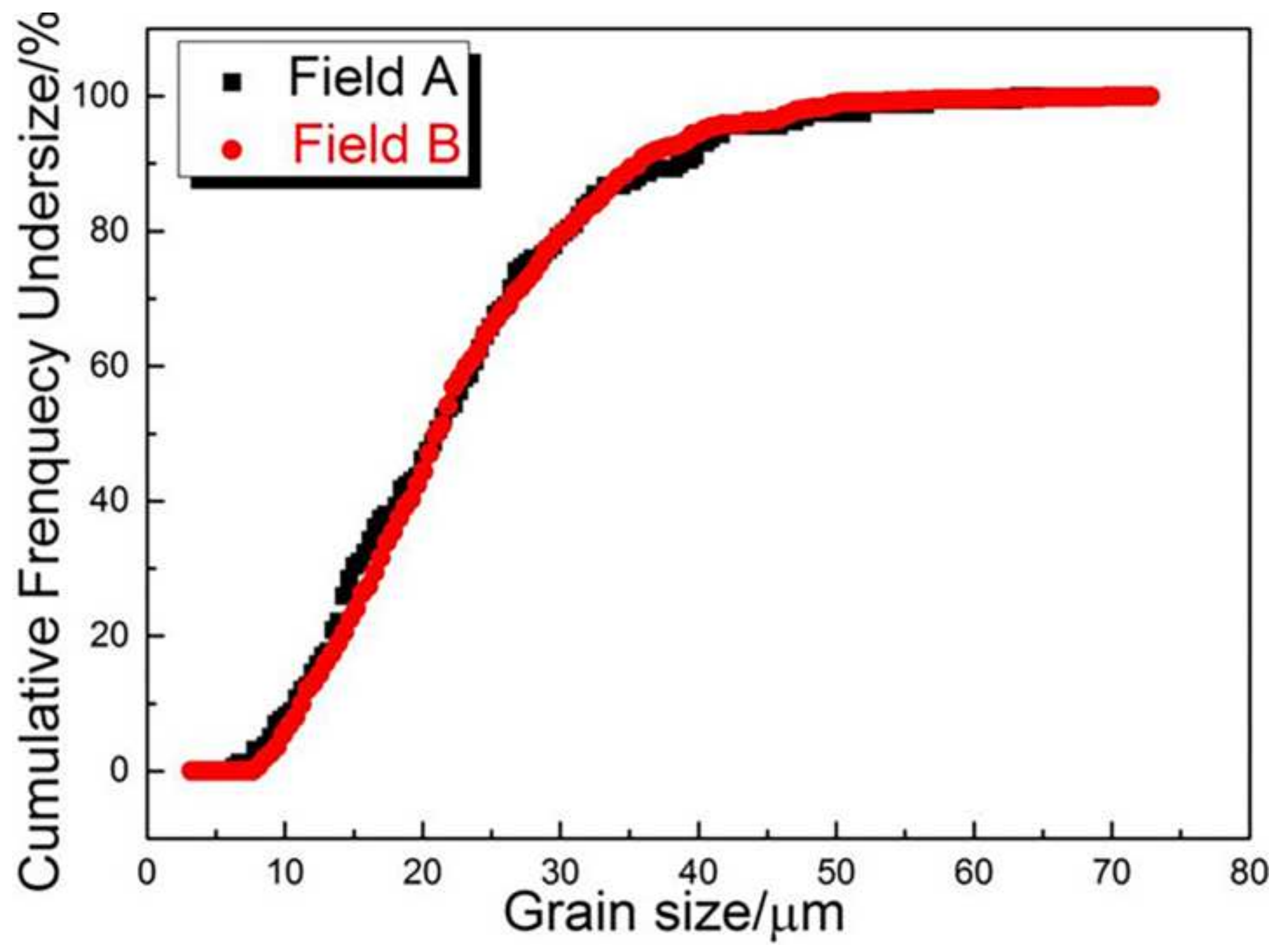




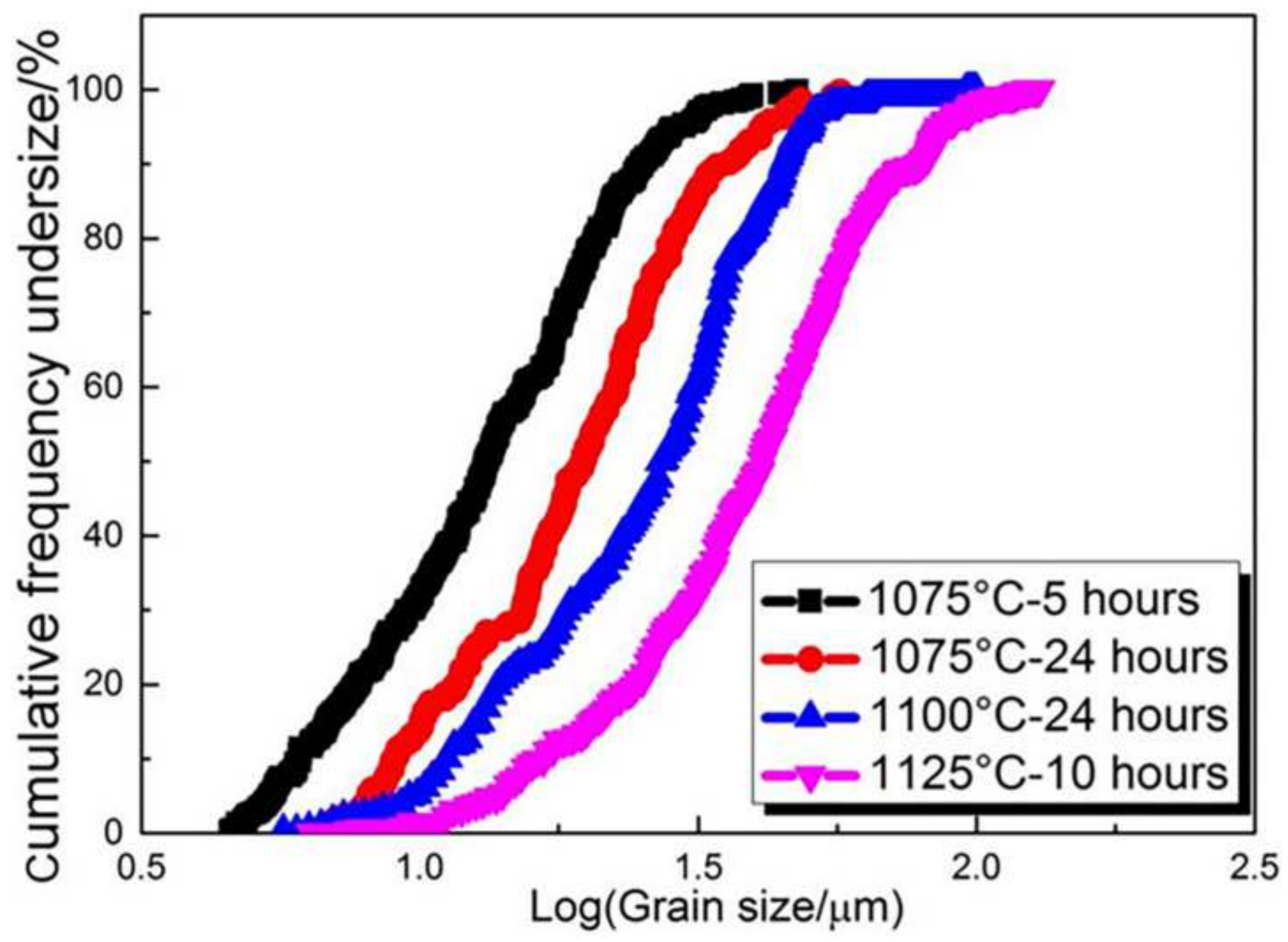




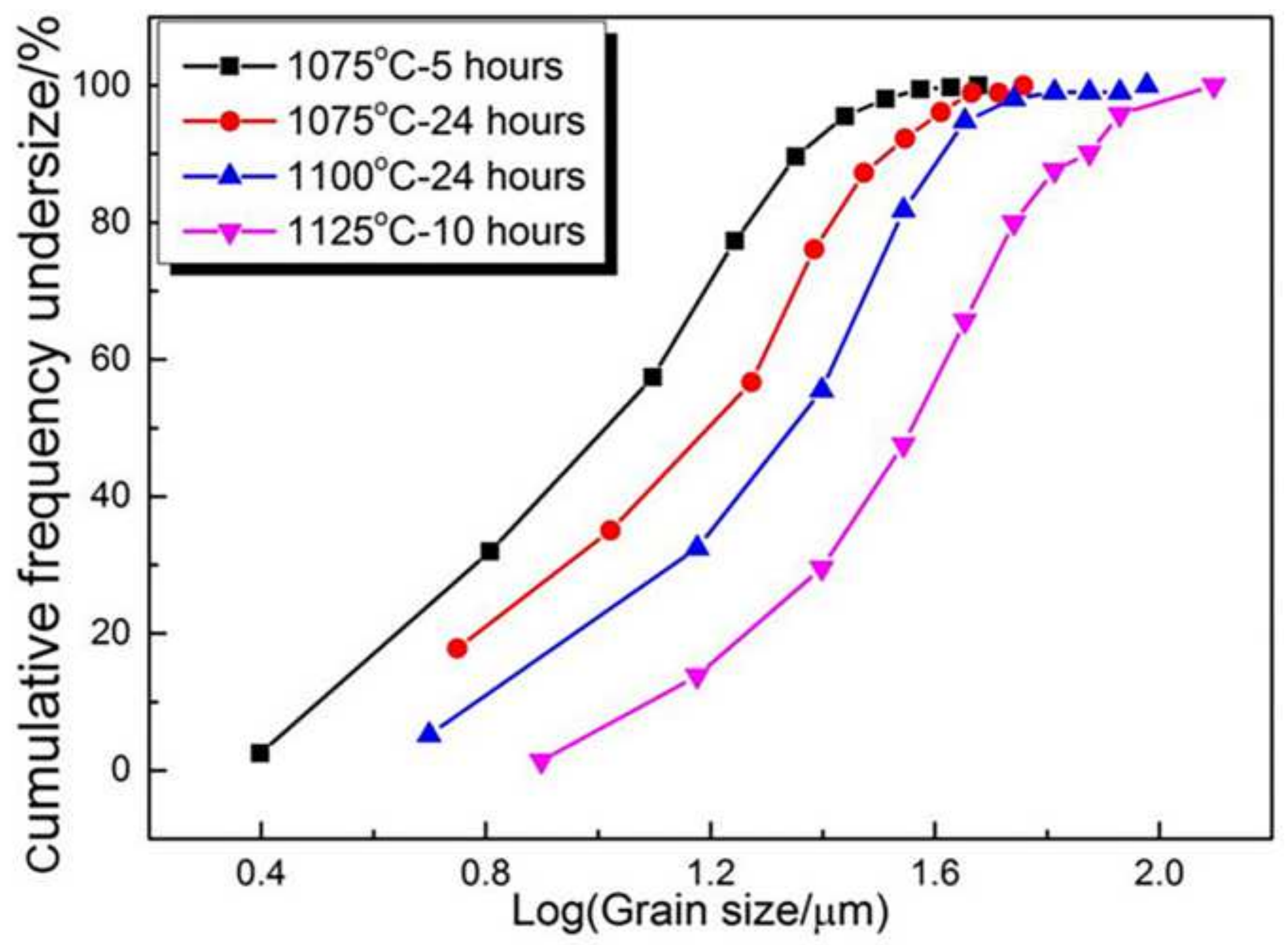




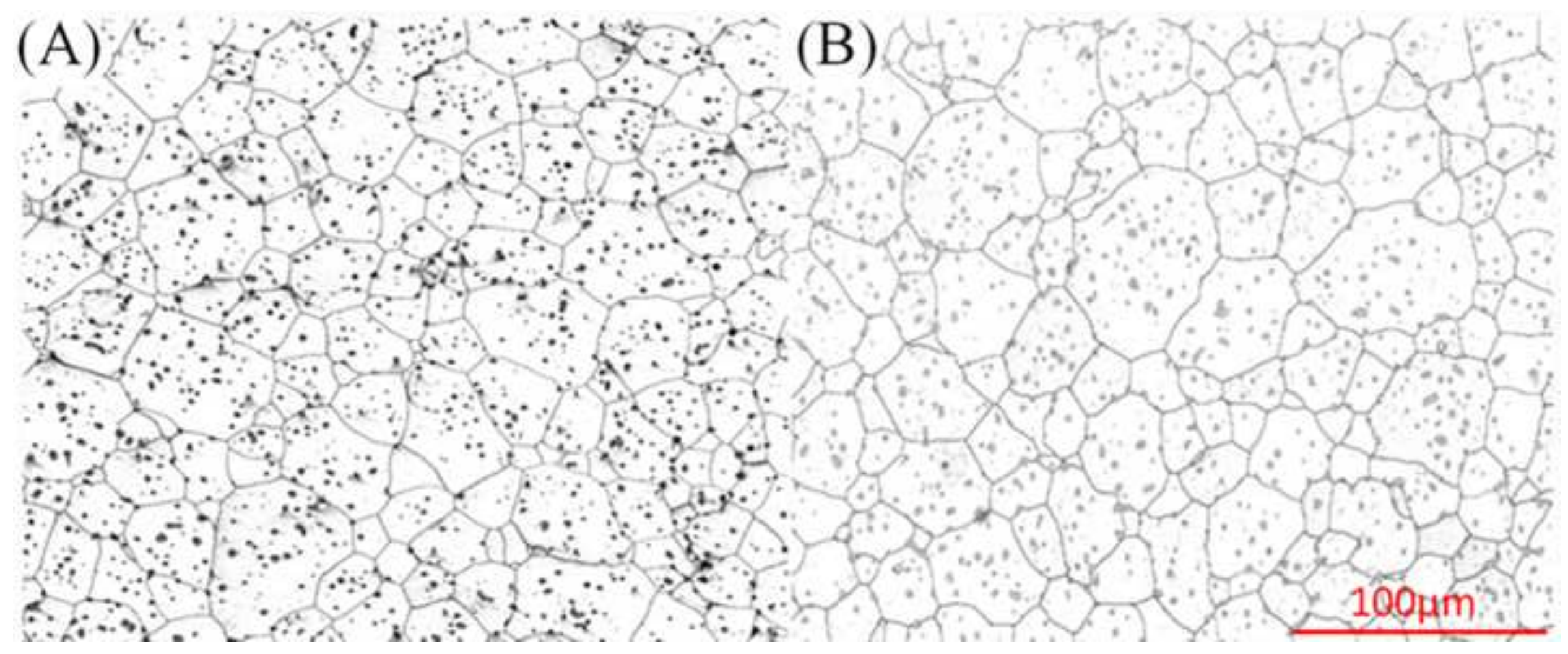




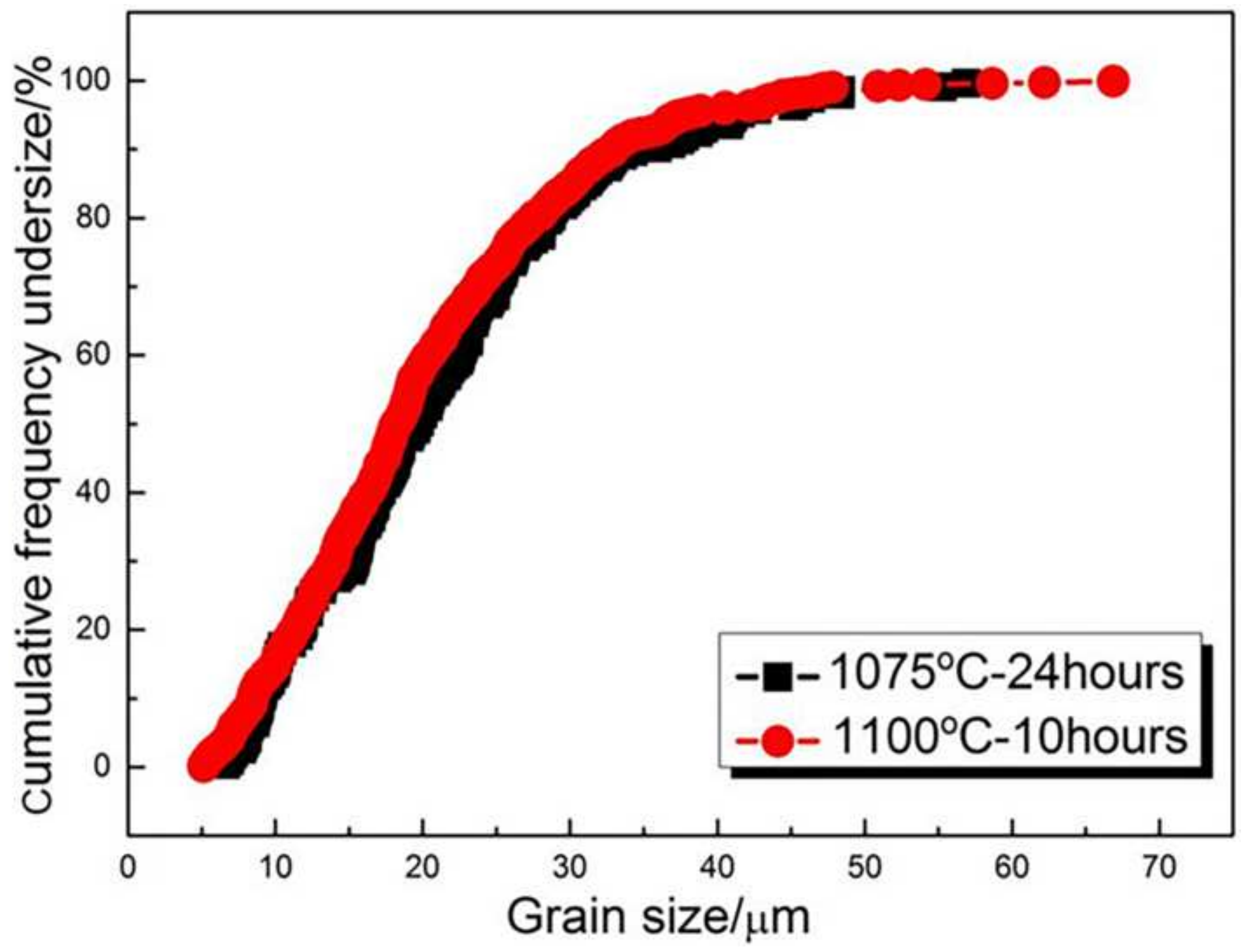



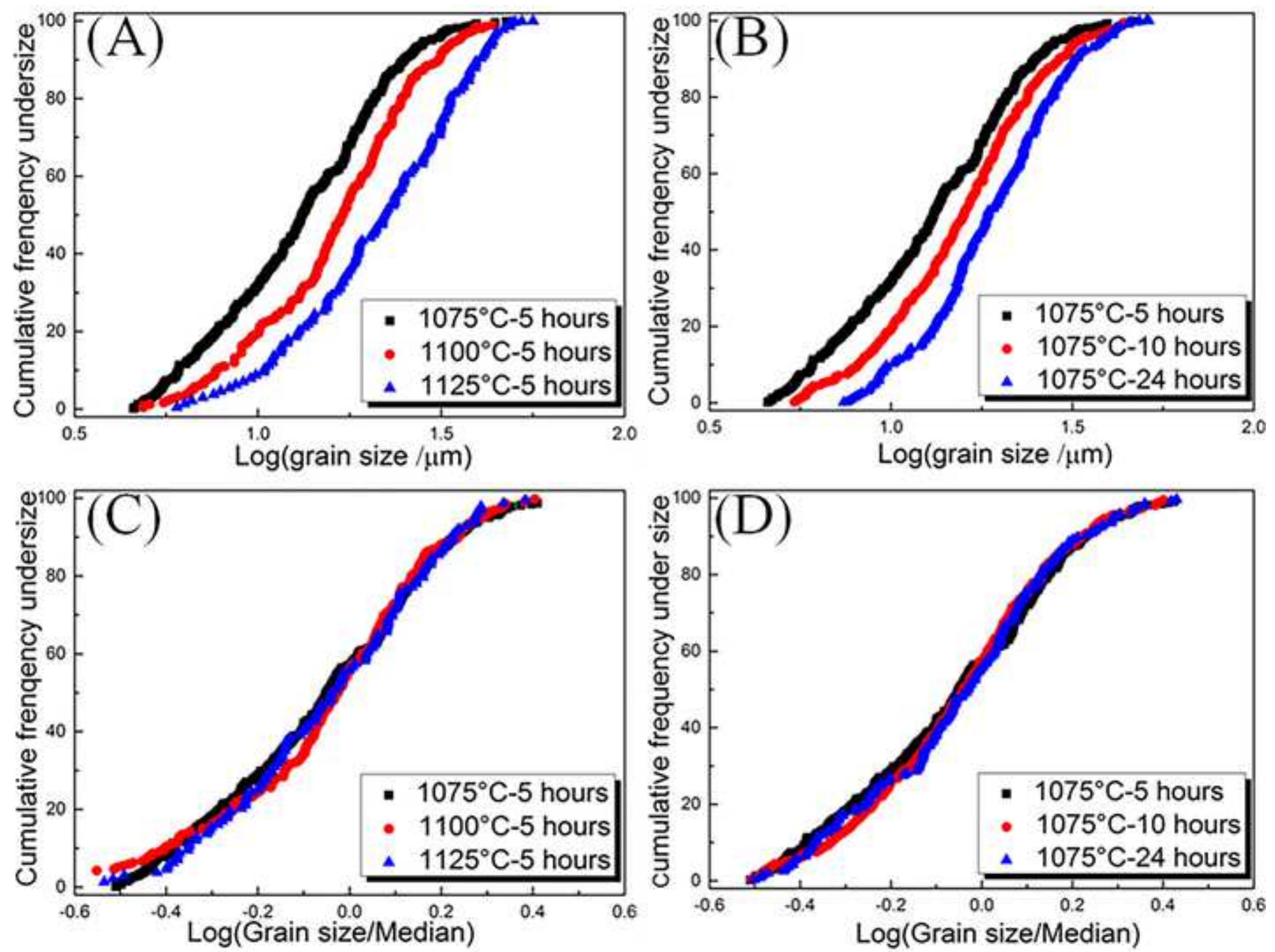


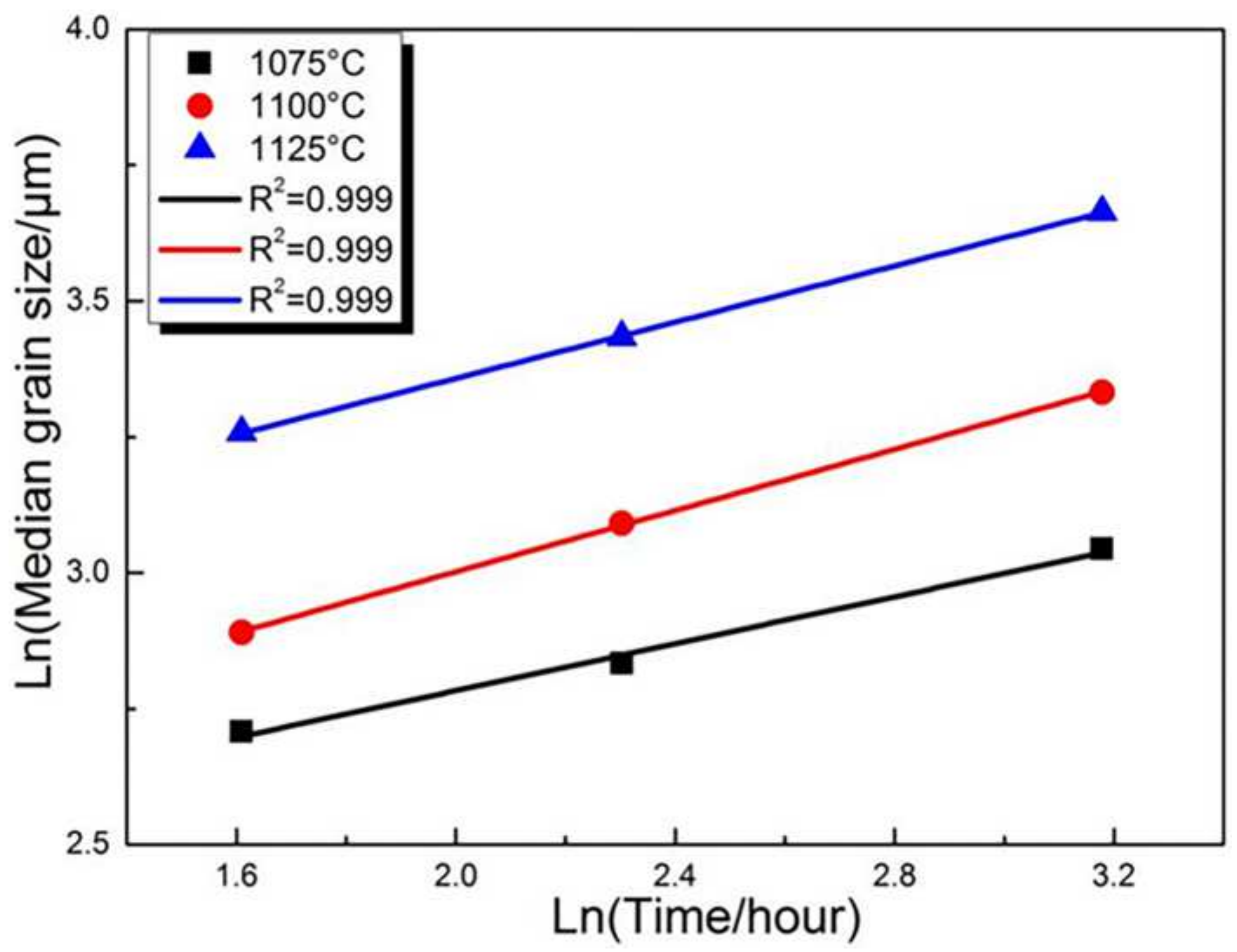



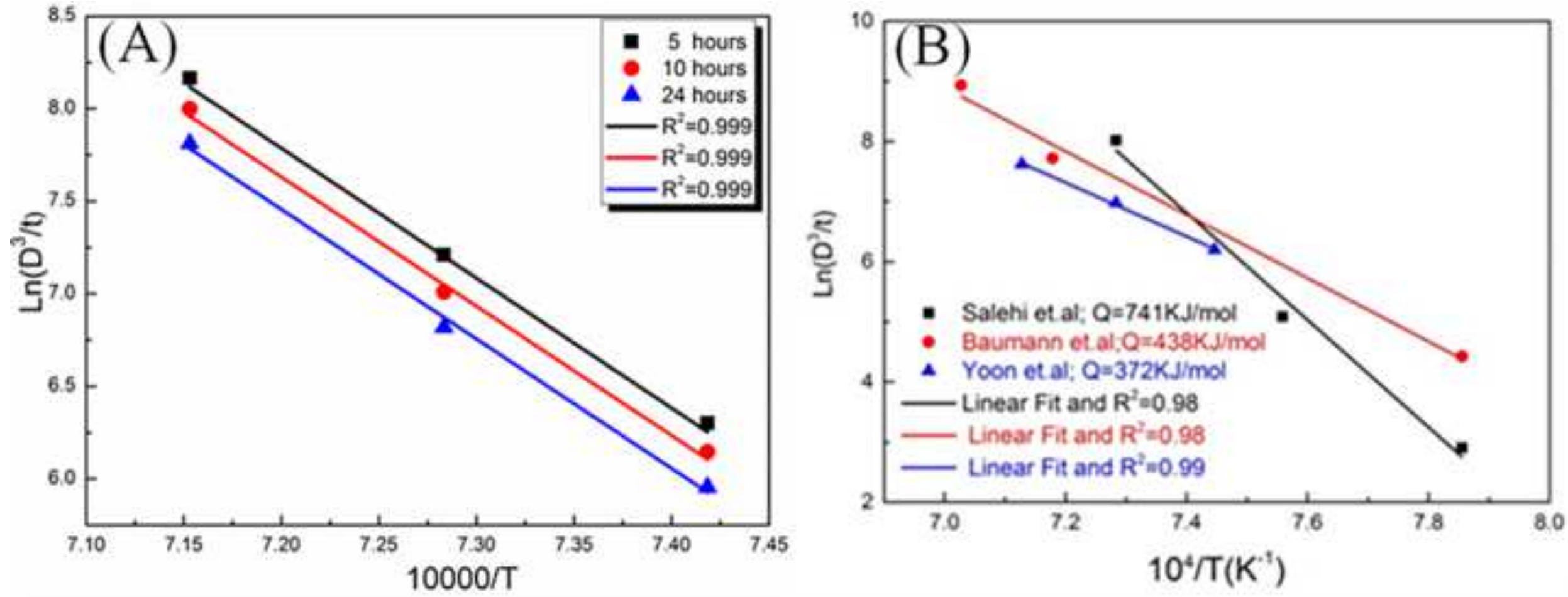


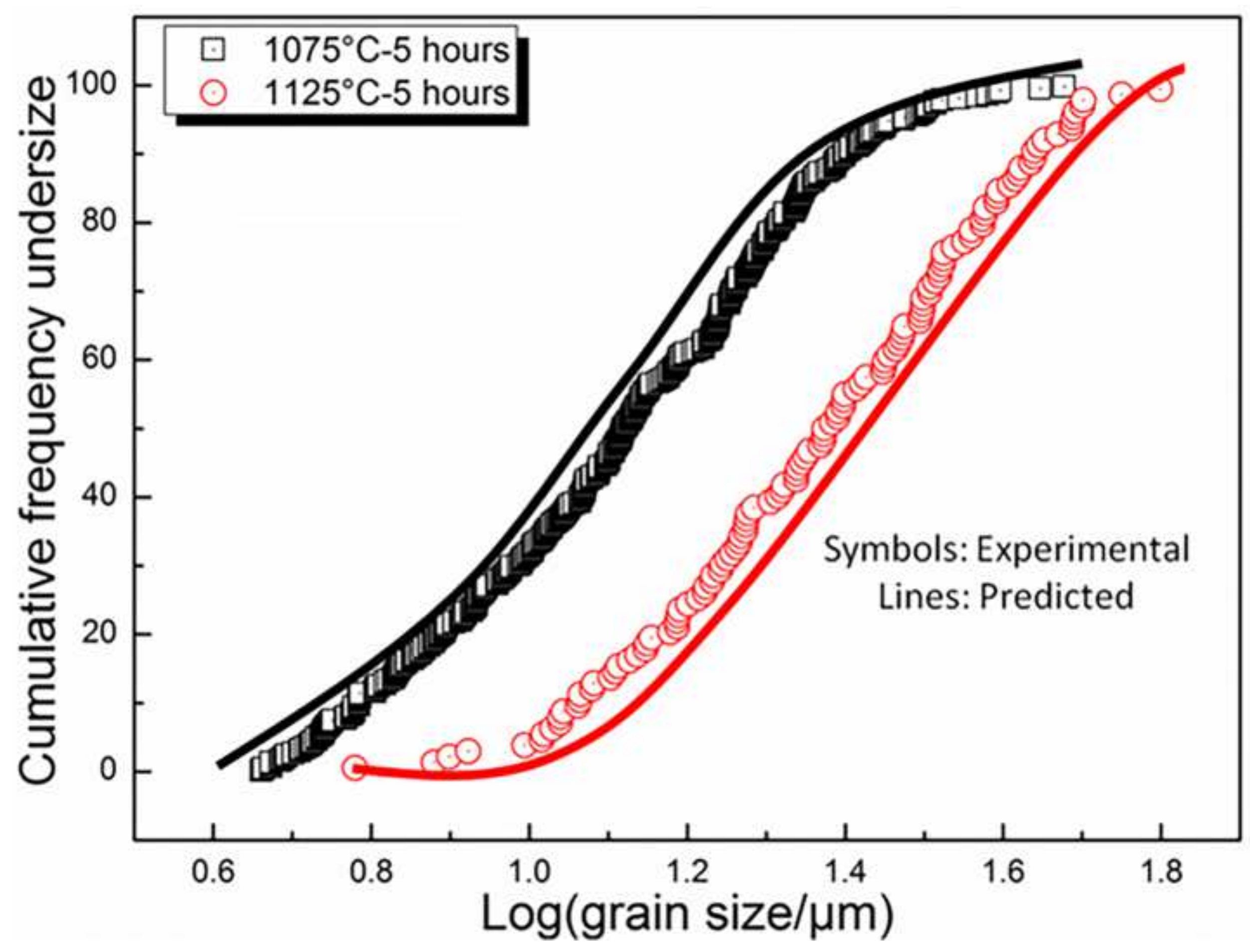


Figure 1 EBSD band contrast micrographs of the BSCF samples sintered at $1100^{\circ} \mathrm{C}$ for 10 hours with two different fields show similar morphology.

Figure 2 Grain size distributions for Figure 1 show the results with reproducibility

Figure 3 Grain size distributions of BSCF having various sintering conditions expose similarity of the profile shapes.

Figure 4 Taking every tenth point of the data in Figure 3 was replotted in the distribution

Figure 5 Scanning Electron micrographs of two BSCF samples sintered at different time-temperature conditions showing similar micro-structural features (A) $1075^{\circ} \mathrm{C}-24$ hours; (B) $1100^{\circ} \mathrm{C}-10$ hours

Figure 6 Measured grain size distributions for the two SEM micrographs of Figure 5 are similar.

Figure 7 Comparison of normalised grain size distributions for different sintering conditions

Figure 8 Time dependence of grain growth kinetics at three different temperatures $\left(1075{ }^{\circ} \mathrm{C}, 1100{ }^{\circ} \mathrm{C}\right.$, and $\left.1125^{\circ} \mathrm{C}\right)$

Figure 9 Arrhenius plot for grain-growth kinetics for BSCF specimens sintered at different conditions

Figure 10 Experimental and predicted GSDs for BSCF sintered at different conditions. 